\title{
Assessment of motivation for treatment in alcohol dependent patients who sought treatment at a specialized medical service
}

\section{Avaliação da motivação para tratamento em pacientes dependentes de álcool que procuram um serviço especializado}

Hercílio Pereira de Oliveira Júnior ${ }^{\mathrm{a}}$ and André Malbergier ${ }^{\mathrm{b}}$

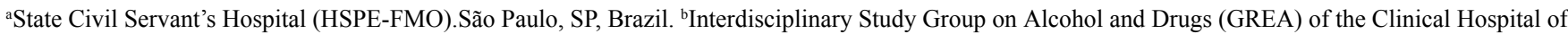
the Medical School of the University of São Paulo. São Paulo, SP, Brazil

\begin{abstract}
Introduction: Motivation is deemed a critical component for interventions intended to change behaviors related to the use of alcohol and other drugs. The classification of patients in 'stages of change' can be a useful tool for the organization and improvement of treating programs.

Methods: This study assessed the stages of change using the scales URICA and SOCRATES in patients who attended two different treating programs for alcohol dependence in a specialized medical service. We performed an analysis of the association between stages of change and demographic aspects. After three months of treatment, patients were reassessed to evaluate their outcome.

Results: In the assessments using URICA, there was an association between stages of change and monthly income and age. There was no evidence that patients move across the stages of change. Using the scale SOCRATES, we found an association between stages of change and monthly income. In the reassessment, there was a significant movement across the stages of change.

Conclusion: Patients who attend two different treating programs may have different motivation profiles. There was no movement congruent with the stage of change model, suggesting that patients may need more than 3 months to obtain significant changes in their motivation.
\end{abstract}

Keywords Alcohol dependence. Motivation. Treatment. Stages of change.

Resumo Introdução: A motivação para tratamento pode ser considerada um componente crítico em intervenções destinadas a mudar comportamentos relacionados ao consumo de álcool e outras drogas. A classificação dos pacientes em "estágios de mudança" pode ser uma ferramenta útil para organização e aperfeiçoamento dos programas de tratamento.

Métodos: Neste estudo, os pacientes que chegam para tratamento de dependência do álcool em dois ambulatórios distintos de um serviço especializado são avaliados através das escalas Socrates e Urica. Realiza-se análise das associações entre estágio de mudança e variáveis sociodemográficas e, após três meses de tratamento, os pacientes são reavaliados para verificar sua evolução.

Resultados: Nas avaliações realizadas com a escala Urica, observou-se associação dos estágios de mudança e as variáveis renda mensal e idade. Não houve mudanças significativas nos estágios nas reavaliações. Na escala Socrates verificou-se associação dos estágios de mudança com a variável renda mensal. Na reavaliação, houve deslocamento significativo dos pacientes através dos estágios de mudança.

Conclusões: Os pacientes encaminhados de maneira distinta a serviços de atendimento podem não apresentar características homogêneas quanto à motivação. Não se verificou deslocamento congruente com o modelo do "ciclo de mudanças", o que pode sugerir que os pacientes precisem de mais de três meses para a obtenção de mudanças significativas em sua motivação.

Descritores Dependência de álcool. Motivação. Tratamento. Estágios de mudança. 


\section{Introduction}

Alcohol and drug abuse is responsible for several public health problems, which importance can be clearly evidenced by several studies highlighting the public resources invested in preventive and treating programs. In the US nearly U $\$ 3,8$ billion are yearly invested. ${ }^{1}$

Therefore, interventions aimed at the increase of the therapeutical efficacy are extremely valuable. Several elements can be related to this efficacy, being the patients' motivation for the treatment one of the most significant ones ${ }^{2}$, and it can be deemed a central feature in dependent behaviors. ${ }^{3}$

The word motivation comes from the Latin root meaning 'move', as an attempt to understand what moves us or the reason why we have certain attitudes ${ }^{4}$. Motivation can be defined as "the likelihood that a person start, keep and stay in a process of specific change's. Motivation is a dynamic process, which undergoes fluctuations along the treatment, a fact described in the Transtheoretical Model that includes several phases related to change in the dependent behavior. ${ }^{6}$

The Transtheoretical Model is a construct composed by 'stages of change', which are: Pre-Contemplation, Contemplation, Determination, Action and Maintenance. Patients in the stage of Pre-Contemplation do not recognize or do not think it is necessary to change their consumption; in the stage of Contemplation, the negative consequences of consumption are considered; in the stage of Action subjects are determined to make a change in their consumption behavior whereas in the stage of Maintenance patients consolidate the strategies that were effective during the recovery.

The understanding of the stages of change, as well as the patients' features regarding their readiness for the treatment, have been deemed fundamental processes at the beginning of any therapeutical intervention ${ }^{7}$, since more motivated patients tend to show better outcomes. ${ }^{8}$

Our study aims at classifying patients in the several stages of change at the beginning of the treatment and three months later, therefore verifying their outcome. Hypotheses to be tested: 1) Patients who spontaneously sought treatment would be in more evolved stages than those referred by their superiors; 2)Patients effectively would move along the stages of change after three months of treatment.

\section{Methods}

This study was developed in the GREA- Interdisciplinary Study Group on Alcohol and Drugs of the Department and Institute of Psychiatry of the Clinical Hospital of the Medical School of the University of São Paulo (Ipq-HC-FMUSP). For our study, we assessed patients who sought treatment in two ambulatories of this service: the General Ambulatory where community patients who spontaneously seek treatment are seen, and the PRODUSP's (Program for Prevention and Treatment of Drug Use in the University of São Paulo) Ambulatory, where University employees are seen and who are generally referred by their superiors.

All patients who sought the mentioned ambulatories from January to December 2000 were invited to participate in the study and were included after signing the informed consent. The inclusion criteria were:

1. Diagnosis of alcohol dependence according to the ICD-10 through the best clinical judgement.

2. Age equal to or above 18 years.

3. Domiciled in the Greater São Paulo.

Exclusionary criteria were: dependence of other psychoactive substances besides alcohol, patients with psychotic or demential disorders.

The sample was composed by 59 patients ( 30 coming from the PRODUSP and 29 from the general ambulatory of the GREA). In the first medical attention patients were assessed regarding their motivation with two scales: SOCRATES (Stages Readiness and Treatment Eagerness Scale) ${ }^{9}$, a 19-item scale which allows the characterization of the stages of Recognition, Ambivalence and Action; and URICA (University of Rhode Island Change Assessment Scale) ${ }^{10}$, composed by 32 items that discriminate between the stages of Pre-Contemplation, Contemplation, Action and Maintenance. These scales had already been translated into Portuguese in other study in our country ${ }^{11}$. After three months 26 patients from the PRODUSP and 22 from the general ambulatory were reassessed using both scales again.

\section{Statistical Analysis}

In order to assess the statistical significance of the associations between stages of change and the institution to which patients were admitted and between these stages and the socioeconomic variables we performed chi-square tests of independence $^{12}$. Due to the relatively small size of the samples we took care to perform exact tests whenever needed.

In order to compare the distributions in the stages of change in the initial assessment and in the reassessment, tests of marginal homogeneity were performed based on Wald's statistics ${ }^{13}$. Below the tables related to these tests we present the value of Wald's statistics (W), the number of degrees of freedom (d.f.) and the corresponding $p$ value. Separate analyses for the two institutions (General Ambulatory and PRODUSP) were performed, including in the analyses only patients who underwent both assessments.

In the sections below we present the analyses related to the stages of change measured in the URICA and SOCRATES scales, respectively. The patients' absolute frequencies are displayed between brackets in the tables of distribution of frequencies.

\section{Results}

The sample was composed by 59 patients, $95 \%$ of whom were males, aging 30 to $50(58 \%)$, mean age of 43 years. They were mostly single (54\%), with less then eight years of schooling $(63 \%)$, with monthly income above R $\$ 500.00$ (near to U\$140.00-150.00 nowadays-NT) $-65 \%, 58 \%$ were employed and drank less than $400 \mathrm{~g}$ alcohol/day. There were no statistically significant differences between patients of the general ambulatory and the PRODUSP regarding the socioeconomic variables described above. 
In the tables, the word Community refers to the patients of the general ambulatory and the word PRODUSP to the patients originated from the University of São Paulo.

\section{Urica Scale}

Table 1 displays the distribution of stages of change, according to the URICA scale, in both ambulatories at the patients' admission to the study:

Of note, the stage Action is predominant among patients of the Community (48.3\%, against $23.3 \%$ of the PRODUSP). In the latter, in turn, the stage of Pre-Contemplation is predominant $(43.3 \%$, against $27.6 \%$ of the Community). The association between the ambulatory and the stages of change, however, is not statistically significant $(\mathrm{p}=0.210)$.

During the reassessments in the general ambulatory, it was verified that out of 8 patients initially classified in the stage of Pre-Contemplation, 6 proceeded in the study and all moved to other stages after three months of treatment (Table 2). Among 5 patients initially classified in the stage of Contemplation there was also a trend of displacement and 4 of them, when reassessed, were in the stage of Action. However, we noticed that among subjects initially classified in the stages of Action and Maintenance, 6 moved to the stage of Pre-Contemplation, 2 to the stage of Contemplation and 3 remained in the stage of Action.

Despite those trends, marginal distributions of stages of change in the initial assessment and in the reassessment were quite close. The test of partial homogeneity was not significant $(p=0.906)$, showing that the rate of subjects classified in each stage in the first assessment and after three months did not have a statistically significant difference.

Behaviors regarding changes of stage after three months of treatment were similar in the PRODUSP and in the Community. Table 3 shows that, among patients initially classified in the stages of Pre-Contemplation and Contemplation, 6 remained in these two stages, 5 moved to Action and 3 to Maintenance. However, there was no difference between the marginal distributions of stages of change in the first assessment and in the reassessment. The test of marginal homogeneity was non-significant $(\mathrm{p}=0.945$ ), what led us to conclude that the proportions of patients in each stage remained constant after three months of treatment. Furthermore, out of the twelve patients initially classified in the stages of Action and Maintenance, 7 moved to Pre-Contemplation, 2 to Contemplation and 3 remained in the same stages, but also without significant statistical association.

According to the URICA scale, there was a statistically significant association between the stages of change, and the patients' age, being older patients classified in more advanced stages $(p=0.047)$. In this assessment the age of 50 was considered as the cut-off point.

Patients with monthly income up to $\mathrm{R} \$ 500$ were concentrated in the stage of Pre-Contemplation (57.1\%), whereas patients with higher income levels were concentrated in the stage of Action (44.7\%). This association was significant $(\mathrm{p}=0.040)$.

Other socio-demographical variables had no association with the stages of change assessed by the URICA scale.

\section{Socrates Scale}

Table 4 demonstrates the distribution of the stages of change

Table 1 - Distribution of frequencies of stages of change University of Rhode Island Change Assessment Scale (URICA) according to the Institution.

\begin{tabular}{|c|c|c|c|c|c|c|c|c|c|c|}
\hline \multirow{3}{*}{$\begin{array}{l}\text { Institution } \\
\text { Community }\end{array}$} & \multicolumn{6}{|c|}{ Stages of change } & \multirow{2}{*}{\multicolumn{2}{|c|}{ Maintenance }} & \multirow{2}{*}{\multicolumn{2}{|c|}{ Total }} \\
\hline & \multicolumn{2}{|c|}{ Pre-contemplation } & \multicolumn{2}{|c|}{ Contemplation } & \multicolumn{2}{|c|}{ Action } & & & & \\
\hline & $27.6 \%$ & $(8)$ & $17.2 \%$ & (5) & $48.3 \%$ & (14) & $6.9 \%$ & (2) & $100.0 \%$ & (29) \\
\hline PRODUSP & $43.3 \%$ & (13) & $16.7 \%$ & (5) & $23.3 \%$ & $(7)$ & $16.7 \%$ & (5) & $100.0 \%$ & (30) \\
\hline Total & $35.6 \%$ & (21) & $16.9 \%$ & (10) & $35.6 \%$ & (21) & $11.9 \%$ & (7) & $100.0 \%$ & (59) \\
\hline
\end{tabular}

$\chi^{2}=4.794 ; p=0.210$

Table 2 - Joint distribution of frequencies of stages of change in the initial assessment and in the reassessment (Community).

\begin{tabular}{|c|c|c|c|c|c|c|c|c|c|c|}
\hline \multirow{3}{*}{$\begin{array}{l}\text { Stage of change - } \\
\text { Assessment } \\
\text { Pre-contemplation }\end{array}$} & \multicolumn{8}{|c|}{ Stages of change - Reassessment } & & \\
\hline & \multicolumn{2}{|c|}{ Pre-contemplation } & \multicolumn{2}{|c|}{ Contemplation } & \multicolumn{2}{|c|}{ Action } & \multicolumn{2}{|c|}{ Maintenance } & \multicolumn{2}{|c|}{ Total } \\
\hline & $0.0 \%$ & $(0)$ & $9.1 \%$ & (2) & $13.6 \%$ & (3) & $4.5 \%$ & (1) & $27.3 \%$ & (6) \\
\hline Contemplation & $4.5 \%$ & (1) & $0.0 \%$ & (0) & $18.2 \%$ & (4) & $0.0 \%$ & (0) & $22.7 \%$ & (5) \\
\hline Action & $22.7 \%$ & (5) & $4.5 \%$ & (1) & $13.6 \%$ & (3) & $0.0 \%$ & $(0)$ & $40.9 \%$ & (9) \\
\hline Maintenance & $4.5 \%$ & (1) & $4.5 \%$ & (1) & $0.0 \%$ & (0) & $0.0 \%$ & (0) & $9.1 \%$ & (2) \\
\hline Total & $31.8 \%$ & (7) & $18.2 \%$ & (4) & $45.5 \%$ & (10) & $4.5 \%$ & (1) & $100.0 \%$ & (22) \\
\hline
\end{tabular}

$W=0.558 ;$ d. $f=3 ; p=0.906$

Table 3 - Joint distribution of frequencies of the stages of change in the initial assessment and in the reassessment (PRODUSP).

\begin{tabular}{|c|c|c|c|c|c|c|c|c|c|c|}
\hline \multirow{3}{*}{$\begin{array}{l}\text { Stage of change - } \\
\text { Assessment } \\
\text { Pre-contemplation }\end{array}$} & \multicolumn{8}{|c|}{ Stage of change - Reassessment } & & \\
\hline & \multicolumn{2}{|c|}{ Pre-contemplation } & \multicolumn{2}{|c|}{ Contemplation } & \multicolumn{2}{|c|}{ Action } & \multicolumn{2}{|c|}{ Maintenance } & \multicolumn{2}{|c|}{ Total } \\
\hline & $15.4 \%$ & (4) & $3.8 \%$ & (1) & $11.5 \%$ & (3) & $7.7 \%$ & (2) & $38.5 \%$ & (10) \\
\hline Contemplation & $3.8 \%$ & (1) & $0.0 \%$ & (0) & $7.7 \%$ & (2) & $3.8 \%$ & (1) & $15.4 \%$ & (4) \\
\hline Action & $19.2 \%$ & (5) & $0.0 \%$ & (0) & $3.8 \%$ & (1) & $3.8 \%$ & (1) & $26.9 \%$ & (7) \\
\hline Maintenance & $7.7 \%$ & $(2)$ & $7.7 \%$ & (2) & $0.0 \%$ & (0) & $3.8 \%$ & (1) & $19.2 \%$ & (5) \\
\hline Total & $46.2 \%$ & $(12)$ & $11.5 \%$ & (3) & $23.1 \%$ & (6) & $19.2 \%$ & (5) & $100.0 \%$ & (26) \\
\hline
\end{tabular}

$W=0.374 ;$ d. $f=3 ; p=0.945$ 
in both ambulatories according to the SOCRATES scale, at the patients' admission in the study:

Table 4 displays the lack of association between ambulatory type and stage of change measured in the SOCRATES scale $(\mathrm{p}=0.769)$.

Table 5 demonstrates the distribution of patients at reassessment according to the SOCRATES scale in the Community, in which most of the 11 patients initially classified in the stage of Ambivalence were classified in the reassessment in the stage of Recognition.

Due to this, the proportion of patients classified in the stage of Recognition in the reassessment (45.5\%) was higher than in the first assessment (18.2\%). Nevertheless, the test of marginal homogeneity was not significant $(\mathrm{p}=0.116)$, that is, we can not state for sure that the marginal distributions of subjects in each stage in the two assessment were different in the studied population.

During the reassessments of the PRODUSP's patients, using the SOCRATES scale, there was no lineal movement of patients along the stages, as well as in the Community (see Table 6). Half of the 14 subjects initially classified in the stage of Ambivalence moved to the stage of Recognition. Furthermore, 4 out of 10 subjects initially assessed in the stage of Action were reassessed in the stage of Recognition.

Due to this, the proportion of subjects classified in the stage of Recognition in the reassessment (50.0\%) was higher than the rate of subjects initially assessed in this stage (7.7\%). The test of marginal homogeneity was significant $(\mathrm{p}=0.000)$, showing that the marginal distributions in both assessments can, in fact, differ in the population (Table 6).

There was a significant association between monthly income and stage of change $(\mathrm{p}=0.043)$. The rate of subjects classified in the stage of Recognition was higher among those with monthly income up to $\mathrm{R} \$ 500$ (28.6\%) than among those with higher income $(5.3 \%)$.

Other socio-demographical variables (gender, marital status, schooling, being regularly employed and amount of alcohol intake) had no association with the stages of changes assessed by the SOCRATES scale.

Summing up the results, the variables age and monthly income showed significant association with the stages of change measured with the URICA scale . The stages of change measured with the SOCRATES scale had a significant association only with the monthly income. Besides, there was no significant difference between the distributions of the stages of change measured with the URICA scale in the first assessment and in the reassessment three months later, both in the Community and in the PRODUSP. According to the SOCRATES scale, there was no significant difference between the distributions of the stages of change in the two assessments of the Community. In the PRODUSP, the initial distribution of the stages of change differed from the distribution in the reassessment.

\section{Discussion}

The assessment of patients during the project showed associations between socio-demographic features and the predominance of some of the stages of change: older patients from the Community showed predominance of more advanced stages (Action), what had been already reported in the literature ${ }^{14}$. It is possible that older patients underwent repeated exposures to treating circumstances, generating changes of attitude ${ }^{15,16}$ which were reflected in the stage of change. This factor, associated to

Table 4 - Distribution of frequencies of stages of change Stages Readiness and Treatment Eagerness Scale (SOCRATES) according to Institution.

\begin{tabular}{|c|c|c|c|c|c|c|c|c|}
\hline \multirow{3}{*}{$\begin{array}{l}\text { Institution } \\
\text { Community }\end{array}$} & \multicolumn{6}{|c|}{ Stages of change } & \multirow{2}{*}{\multicolumn{2}{|c|}{ Total }} \\
\hline & \multicolumn{2}{|c|}{ Recognition } & \multicolumn{2}{|c|}{ Ambivalence } & \multicolumn{2}{|c|}{ Action } & & \\
\hline & $17.2 \%$ & (5) & $51.7 \%$ & (15) & $31.0 \%$ & (9) & $100 \%$ & (29) \\
\hline PRODUSP & $10.0 \%$ & (3) & $53.3 \%$ & (16) & $36.7 \%$ & (11) & $100 \%$ & (30) \\
\hline Total & $13.6 \%$ & (8) & $52.5 \%$ & (31) & $33.9 \%$ & (20) & $100 \%$ & (59) \\
\hline
\end{tabular}

$\chi^{2}=0.716 ; p=0.769$

Table 5 - Joint distribution of frequencies of the stages of change in the initial assessment and in the reassessment (Community).

\begin{tabular}{|c|c|c|c|c|c|c|c|c|}
\hline \multirow{2}{*}{\multicolumn{2}{|c|}{$\begin{array}{l}\text { Stage of change - } \\
\text { Assessment }\end{array}$}} & & \multicolumn{4}{|c|}{ Stage of change - Reassessment } & \multirow{2}{*}{\multicolumn{2}{|c|}{ Total }} \\
\hline & & Recognition & \multicolumn{2}{|c|}{ Ambivalence } & \multicolumn{2}{|c|}{ Action } & & \\
\hline Recognition & $9.1 \%$ & $(2)$ & $0.0 \%$ & $(0)$ & $9.1 \%$ & $(2)$ & $18.2 \%$ & $(4)$ \\
\hline Ambivalence & $36.4 \%$ & (8) & $9.1 \%$ & (2) & $4.5 \%$ & (1) & $50 ., 0 \%$ & $(11)$ \\
\hline Action & $0.0 \%$ & (0) & $18.2 \%$ & (4) & $13.6 \%$ & (3) & $31.8 \%$ & (7) \\
\hline Total & $45.5 \%$ & (10) & $27.3 \%$ & (6) & $27.3 \%$ & (6) & $100.0 \%$ & $(22)$ \\
\hline
\end{tabular}

$W=4.313 ;$ d.f. $=2 ; p$-value $=0.116$

Table 6 - Joint distribution of frequencies of the stages of change in the initial assessment and in the reassessment (PRODUSP).

\begin{tabular}{|c|c|c|c|c|c|c|c|c|}
\hline \multicolumn{2}{|c|}{$\begin{array}{l}\text { Stage of change - } \\
\text { Assessment }\end{array}$} & Recognition & \multicolumn{2}{|c|}{ Ambivalence } & \multicolumn{2}{|c|}{ Action } & \multicolumn{2}{|c|}{ Total } \\
\hline Recognition & $7.7 \%$ & (2) & $0.0 \%$ & (0) & $0.0 \%$ & (0) & $7.7 \%$ & (2) \\
\hline Ambivalence & $26.9 \%$ & (7) & $15.4 \%$ & (4) & $11.5 \%$ & (3) & $53.8 \%$ & (14) \\
\hline Action & $15.4 \%$ & (4) & $0.0 \%$ & (0) & $23.1 \%$ & (6) & $38.5 \%$ & (10) \\
\hline Total & $50.0 \%$ & (13) & $15.4 \%$ & (4) & $34.6 \%$ & (9) & $100.0 \%$ & (26) \\
\hline
\end{tabular}

$W=24.545 \cdot d . f=2 ; p=0.000$ 
the current disposition to stop drinking, could predict the probability of the success of the therapy ${ }^{17}$. Older patients, contrarily to what is generally expected, have also already shown a lower frequency of social problems linked to alcoholism and of associated health problems. ${ }^{18}$

A significant association between the patients' income and the stages of motivation was found. Patients with higher income were in more advanced stages, whereas patients with lower income were predominantly in more 'primitive' stages, and generally, had a higher occurrence of the stage of Pre-Contemplation when compared to the literature ${ }^{19}$. Patients in PreContemplation could be generally considered as less aware of their drinking, less willing to accept help and less likely to finish successfully the treatment. ${ }^{20}$

Patients with lower income and financial difficulties may have more problems to obtain satisfactory results in their treatment $^{21}$. Complementarily, there is evidence that patients with stable socio-economic conditions have better results regarding withdrawal than those in non-favorable conditions ${ }^{22}$. However, other study did not find association between socio-demographic variables and the distribution of stages of change ${ }^{23}$. The study of these variables may indicate which aspects are connected to the heterogeneity of responses of patients to specific treatments.

We found a predominance of the stage of Pre-Contemplation among patients at the initial phase of the treatment in the PRODUSP, whereas in the Community the stage of Action was predominant. Therefore, PRODUSP's patients would be in a lower stage in the cycle of changes, what may be connected to their non-voluntary referral to treatment, which many times was indicated by their superiors. On the other hand, patients of the Community were in a more advanced stage, what may be connected to their active search for treatment. In fact, the classification of patients in the stage of Action has already been demonstrated to be directly related to better results ${ }^{24}$. Patients who enter treating programs in more 'primitive' stages of the cycle of changes, that is, less motivated, may have lower responses to treatment. Other studies observed that among dependent patients who come for treatment only nearly $10-15 \%$ are in the stage of Action, what would be the most indicated to start a treating program. Nearly $30-40 \%$ are in the stage of Contemplation and $50-60 \%$ in the stage of Pre-Contemplation. ${ }^{25}$

In our study, assessments with the SOCRATES and URICA scales showed some differences regarding the distributions of patients in the stages of change and there was some discrepancy between both scales, what had been already observed in other studies ${ }^{26}$, probably due to differences in the definitions of the stages in the two scales or to the existence of non-yetdefined stages.

The idea that patients proceed through stages of motivation to successfully solving a problem is already known in the literature about dependence ${ }^{27}$. The expectations about the model described by Prochaska and DiClemente rely on the possibility of including it in the motivational interview ${ }^{28}$ and of using it as a strategy to solve the issue of ambivalence.
The movement of patients through the stages of change during the treatment was studied mainly among smoking patients and deserves some considerations: patients often do not show a lineal movement through the stages and the probability of the patient moving to the immediately subsequent or more evolved stage is lower than the probability of moving to any stage $^{29}$. Others claim that the stages can occur more regularly. ${ }^{30}$

In one study ${ }^{31}$ involving a great number of patients it was verified that only $16 \%$ of the patients had a stable progress through the stages within a two-year period and no subject showed a stable progression for three or more stages, whereas $36 \%$ of the patients remained in the same stage along the study.

In our study, there was no statistical evidence that patients had steadily progressed through the stages of change. The issue to be posed has two aspects: either patients did not improve because the treatment was not effective or the scales have not detected this improvement. In the PRODUSP there was a statistically significant movement of patients of more advanced stages (Ambivalence and Action) to the stage of Recognition. Some hypotheses may justify this finding: PRODUSP's patients were employed, were referred to the treatment by their superiors, making the intervention compulsory. Nevertheless, we must highlight that the reassessments were performed three months after the first interview while several studies report the need of at least six months to verify any significant dislocation. ${ }^{32}$

The utilization of classifications of patients according to their stages of change in interventions aimed at changing addictive behaviors is being widely discussed in the specialized literature. Some authors support their use an actual, practical and widely- used alternative to detect behavioral changes ${ }^{33}$, while others question their power of predicting effective changes in patients ${ }^{26}$. The main criticism is connected to the possibility of stages not being mutually exclusive and to the scarcity of studies in which patients perform lineal movements through the stages. ${ }^{34}$ Supporters of the model claim that the stage of change in which the patient is situated can supply important elements about the treatment of choice. Therapies aimed at subjects in the stage of Action can be more efficient than interventions aimed at patients in the stages of Pre-Contemplation or Contemplation. Among patients who entered in a program under such conditions, that is, receiving appropriate and timely treatment in the moment they were evolving in the cycle of changes, near $94 \%$ remained abstinent in the six consecutive months ${ }^{22}$. Several studies ${ }^{35,36}$ evaluated manuals aimed at applying specific therapeutical interventions according to the patients' previous classification in the stages of change, but they could not obtain results clearly indicative of the benefits of this kind of treatment.

Motivation or intention to change can be rather considered as a 'continuum'. In this way, it is more rational to think in terms of 'states of change' and not of 'stages of change' as it is impossible to verify if patients have a lineal movement between consecutive stages ${ }^{37}$. The utilization of stages of change should be considered as a useful alternative to give patients a model of an ideal change, that is, of how they should change. 
Therefore, the planning of more efficient interventions in the area of addiction can be improved.

Some limitations of our study are the short period between assessments and reassessments ( 3 months), the lack of followup of patients who withdrew the research and the relatively small sample size, diminishing the likelihood of obtaining a statistical significance for some trends, such as the predominance of patients in more advanced stages in the Community and less advanced in the PRODUSP.

\section{References}

1. Huber JH, Pope GC, Dayhoff DA. National and state spending on specialty alcoholism treatment: 1979 and 1989. Am J Public Health 1994;84(10):1662-6.

2. Deci EL, Ryan RM. Intrinsic motivation and self-determination in human behavior. New York: Plenum; 1985.

3. Glautier S, Rigney U, Willner P. Motivation for alcohol assessed by multiple variable interval schedule behaviour: effects of reward size and alcohol cues. Behav Pharm 2001;12(2):81-9.

4. Wade C, Tarvis C. Psychology. New York: Harper Collins; 1992.

5. Miller WR. Motivation for treatment: a review with special emphasis on alcoholism. Psychol Bull 1985;98:84-107.

6. Prochaska JO, DiClemente CC. Transtheoretical therapy: Toward a more integrative model of change. Psychother Theor Res Prac 1982;19:276-8.

7. O'Connor PG, Samet JH. The substance-using human immunodeficiency virus patient: approaches to outpatient management. Am J Med 1996;101:435-44.

8. McKay JR, Weiss RV. A review of temporal effects and outcome predictors in substance abuse treatment studies with long-term follow-ups. Preliminary results and methodological issues. Eval Rev 2001;25(2):113-61.

9. Miller WR, Tonigan JS. Assessing drinkers motivation for change: the stages of change readiness and treatment eagerness scale (SOCRATES). Psychol Addict Behav 1996;10:81-9.

10. McConnaughy EA, Prochaska JO, Velicer WF. Stages of change in psychotherapy: measurement and sample profiles. Psychother Theo Res Prac 1983;20:368-75.

11. Figlie NB. Motivação em alcoolistas tratados em ambulatório específico para alcoolismo e em ambulatório de gastroenterologia [Tese de mestrado]. São Paulo: Universidade Federal de São Paulo, Escola Paulista de Medicina; 1999.

12. Bussab WO, Morettin PA. Estatística básica. São Paulo: Atual; 1987.

13. Agresti, A. Categorical Data Analysis. New York: John Wiley; 1990. p. 558.

14. Nigg CR, Burbank PM, Paduka C, Rossi JS, Velicer WF, Laforge RG, Prochaska JO. Stages of change across ten health risk behaviors. Gerontologist 1999;39(4):473-82.

15. Humphreys K, Moos RH, Cohen C. Social and community resources and long-term recovery from treated and untreated alcoholism. J Stud Alcohol 1997;58(3):231-8.

16. Cunningham JA, Lin E, Ross HE. Factors associated with untreated remissions from alcohol abuse or dependence. Addict Behav 2000;25(2):317-21.

17. Sutton S R. Smoking attitudes and behavior: applications of Fishbein and Ajzen's theory of reasoned action to predicting and understanding smoking decisions. Smok Hum Behav 1989;289-312.

18. Neve RJ, Lemmens PH, Drop MJ. Older and younger male alcoholics in outpatient treatment. Addict Behav 1999;24(5):661-72.

19. Rumpf HJ, Hapke U, John U. Previous help seeking and motivation to change drinking behaviors in alcohol dependent general hospital patient. Gen Hosp Psychiatr 1997;25:238-46.

\section{Conclusions}

Summing up, our study has found evidence that patients distinctly referred to treating programs can have non-homogeneous characteristics regarding their motivation, what could justify more specific interventions taking into account the patient's motivational aspect, according to the structure of the supplied service. In this study we did not verify a lineal progression of patients between the stages of the 'cycle of changes' in the period of three months between the assessments.

20. Edens JF, Willouhghby FW. Motivational patterns of alcohol dependent patients: a replication. Psychol Addict Behav 2000;14(4):397-400.

21. Seilhamer R, Jacob T. Alcoholism and family interaction: an experimental paradigm. Am J Drug Abus 1989;15(1):73-91.

22. Kissin B, Platz A, Su WH. Social and psychological factors in the treatment of chronic alcoholism. J Psychiatr Res 1970;8:13-27.

23. Willoughby FW, Edens JF. Construct validity and predictive utility of the stages of change scale for alcoholics. J Subst Abuse 1996;8(3):275-91.

24. Prochaska JO, DiClemente CC, Norcross JC. In search of how people change. Am Psychol 1992;47:1102-14.

25. Gottlieb NH, Gavalotti C, McCuan RS, McAlister AL. Specification of a social cognitive model predicting smoking cessation in a MexicanAmerican population: a prospective study. Cognitive Ther Res 1990;14:529-42.

26. Sutton SR. Back to the drawing board? A review of applications of the transtheoretical model to substance use. Addict 2001;96(1):175-86.

27. Kanfer HF, Grimm JL. Managing clinical change: a process model of therapy. Behav Modific 1980;4:419-44.

28. Miller WR. Motivational interviewing with problem drinkers. Behav Psychother 1983;11:147-72.

29. Martin RA, Velicer WF, Prochaska JO. Latent transition analysis to the stages of change for smoking cessation. Addict Behav 1996;21(1):67-80.

30. Velicer WF, Norman GJ, Fava JL, Prochaska JO. Testing 40 predictions from the transtheoretical model. Addict Behav 1999;24(4):455-69.

31. Prochaska JO, Velicer WF, Guardagnoli E, Rossi JS, DiClemente CC. Patterns of changes: dynamic typology applied to smoking cessation. Multivar Behav Res 1991;26:83-107.

32. Gavin DR, Sobell LC, Sobell MB. Evaluation of readiness to change questionnaire with problem drinkers in treatment. J Subst Abuse 1998;10(1):53-8.

33. Peteet JR, Brenner S, Curtis D. A stage of change approach to addiction in the medical setting. Gen Hosp Psychiatr 1998;20(5):267-73.

34. Littel JH, Girvin H. Stages of change. A critiscim. Behav Modif 2002;26(2):223-73.

35. Velicer WF, Prochask JO, Bellis JM. An expert system intervention for smoking cessation. Addict Behav 1993;18:269-90.

36. Prochaska JO, DiClemente CC, Velicer WF, Rossi JS. Standardized individualized interactive, and personalized self-help programs for smoking cessation. Heal Psychol 1993;12:399-405.

37. Edwards G, Dare C. Psychotherapy, psychological treatments and addictions. Cambridge: Cambridge University Press; 1996.

\section{Correspondence:}

Hercílio Pereira de Oliveira Júnior

Rua Nunes Siqueira, 75 Penha

03604-050 São Paulo, SP, Brazil

E-mail: herciliodeoliveira@ig.com.br 